\title{
Correction to: Daily gridded temperature and precipitation datasets over the Black Sea catchment: 1961-1990 and climate change scenarios for 2071-2100
}

\author{
Ana Gago-Silva ${ }^{1}$ (D) Anthony Lehmann ${ }^{1,2} \cdot$ Stéphane Goyette ${ }^{3,4}$ \\ Published online: 17 July 2020 \\ (C) Springer-Verlag GmbH Austria, part of Springer Nature 2020
}

Correction to: Theoretical and Applied Climatology

https://doi.org/10.1007/s00704-020-03147-x

The original version of this article unfortunately contained mistakes. The original version of this article contains a typographical error in Data. Figures 10, 14, 17 and 19 were incorrect. The corrected figures are given below.

The authors apologize for any inconvenience caused.

The original article has been corrected.

Publisher's note Springer Nature remains neutral with regard to jurisdictional claims in published maps and institutional affiliations.

The online version of the original article can be found at https://doi.org/ 10.1007/s00704-020-03147-x

Ana Gago-Silva

anagagodasilva@gmail.com

1 Institute for Environmental Sciences, enviroSPACE Laboratory, University of Geneva, Bd. Carl-Vogt 66, Geneva, Switzerland

2 Department F.-A. Forel of Environmental and Aquatic Sciences, University of Geneva, Bd. Carl-Vogt 66, Geneva, Switzerland

3 Institute for Environmental Sciences, Nonlinearity and Climate Group, University of Geneva, Bd. Carl-Vogt 66,

Geneva, Switzerland

4 Group of Applied Physics, University of Geneva, 22 Chemin de Pinchat, Geneva, Switzerland 

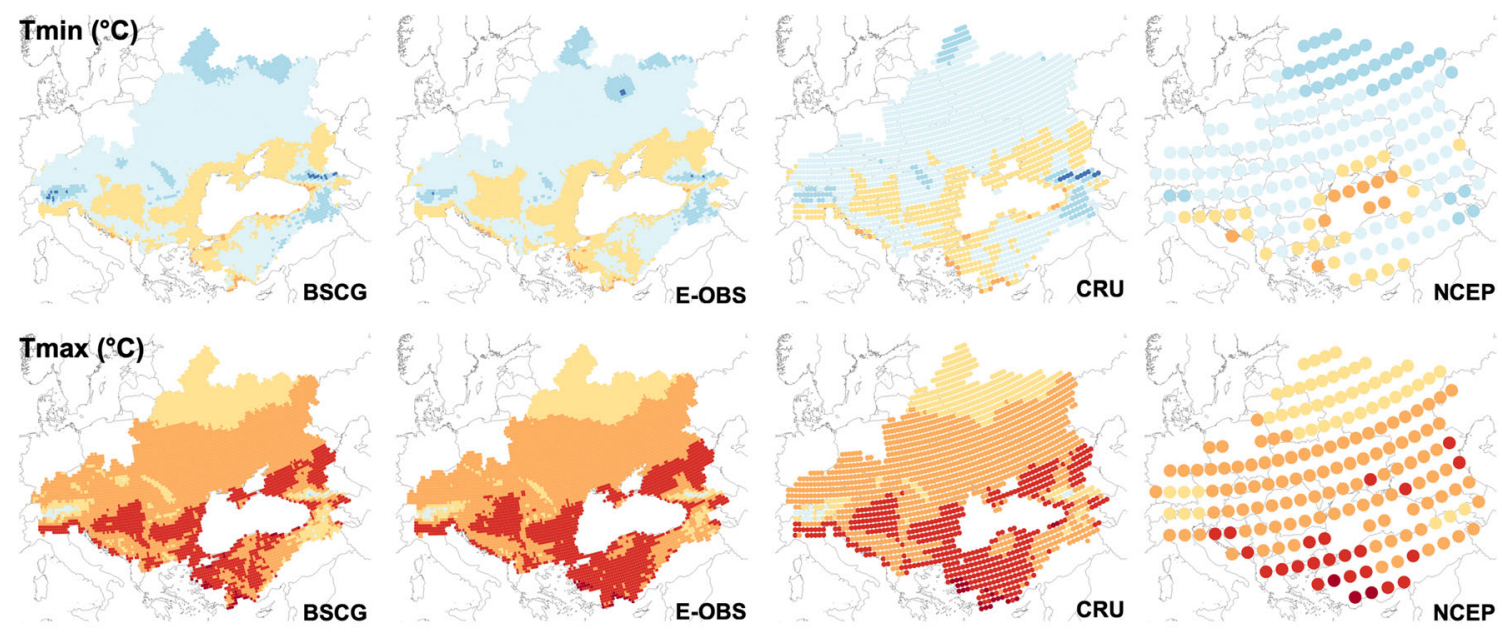

$\operatorname{Tmin} / \operatorname{Tmax}\left({ }^{\circ} \mathrm{C}\right)$

$-10,0:-5,0$

$\begin{array}{ll}0,0: 5,0 & -10,0: 15,0 \\ 5,0: 10,0 & \bullet 15,0: 20,0\end{array}$

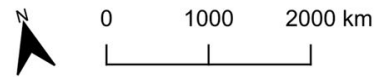

Fig. 10 Average Tmin and Tmax for the historic period (1961-1990), for the BSC grid dataset, the CRU and NCEP datasets
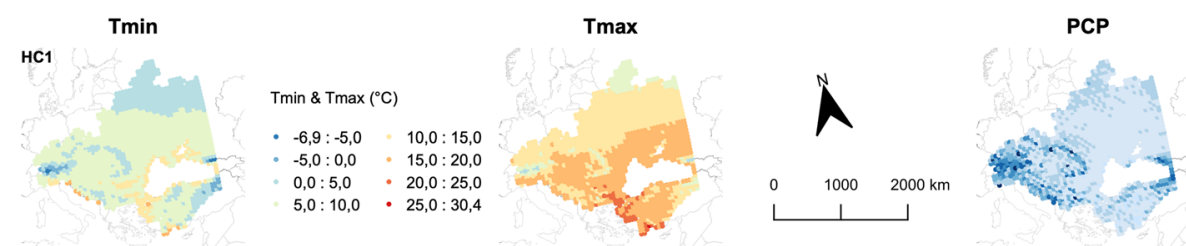

$\mathrm{PCP}(\mathrm{mm} / \mathrm{month})$

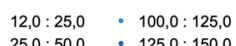

$25,0: 50,0 \quad 125,0: 150,0$

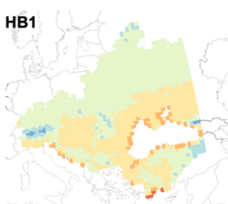

HS1

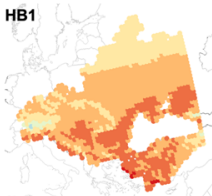

HS1
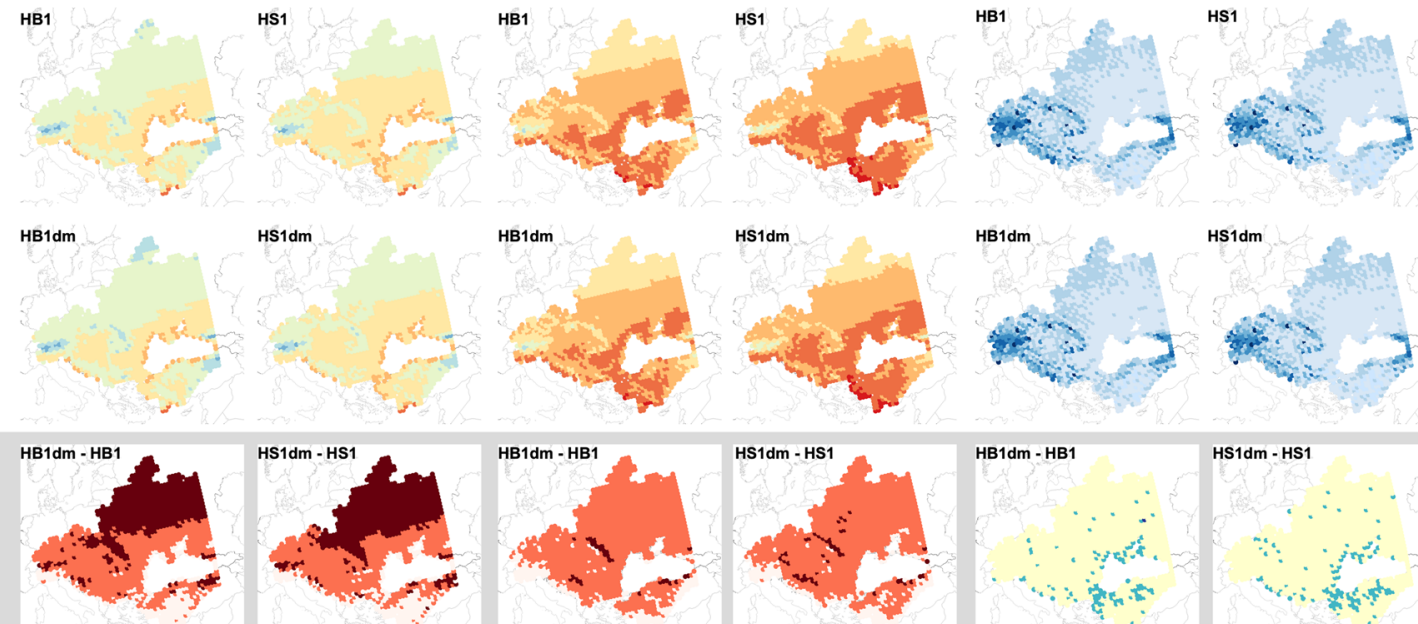

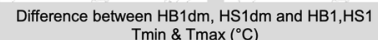

- $-0,63:-0,47 \quad-0,47:-0,32$

$-0,32:-0,16$
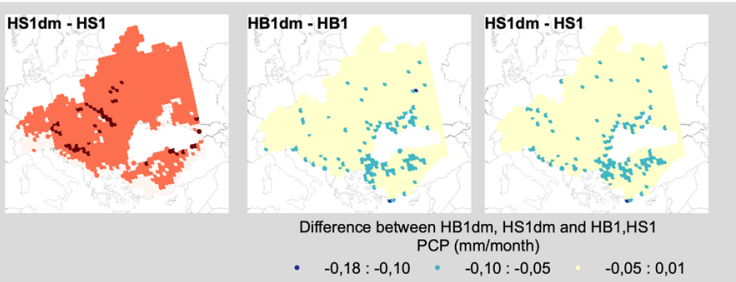

Fig. 14 PRUDENCE HIRHAM mean Tmin, Tmax, and cumulative PCP for the $\mathrm{BSC}$ for the control period ( $\mathrm{HC} 1$ ), each climate emission scenario during 2071-2100 (HB and HS1) and modelled climate emission

scenario with the DM (HB and HS1). The bottom maps show the differences between the reference HB1 and HS1 and the results obtained with the DM (HB1dm and HS1dm) 
Mean seasonal cumulative PCP ( $\mathrm{mm} /$ month)
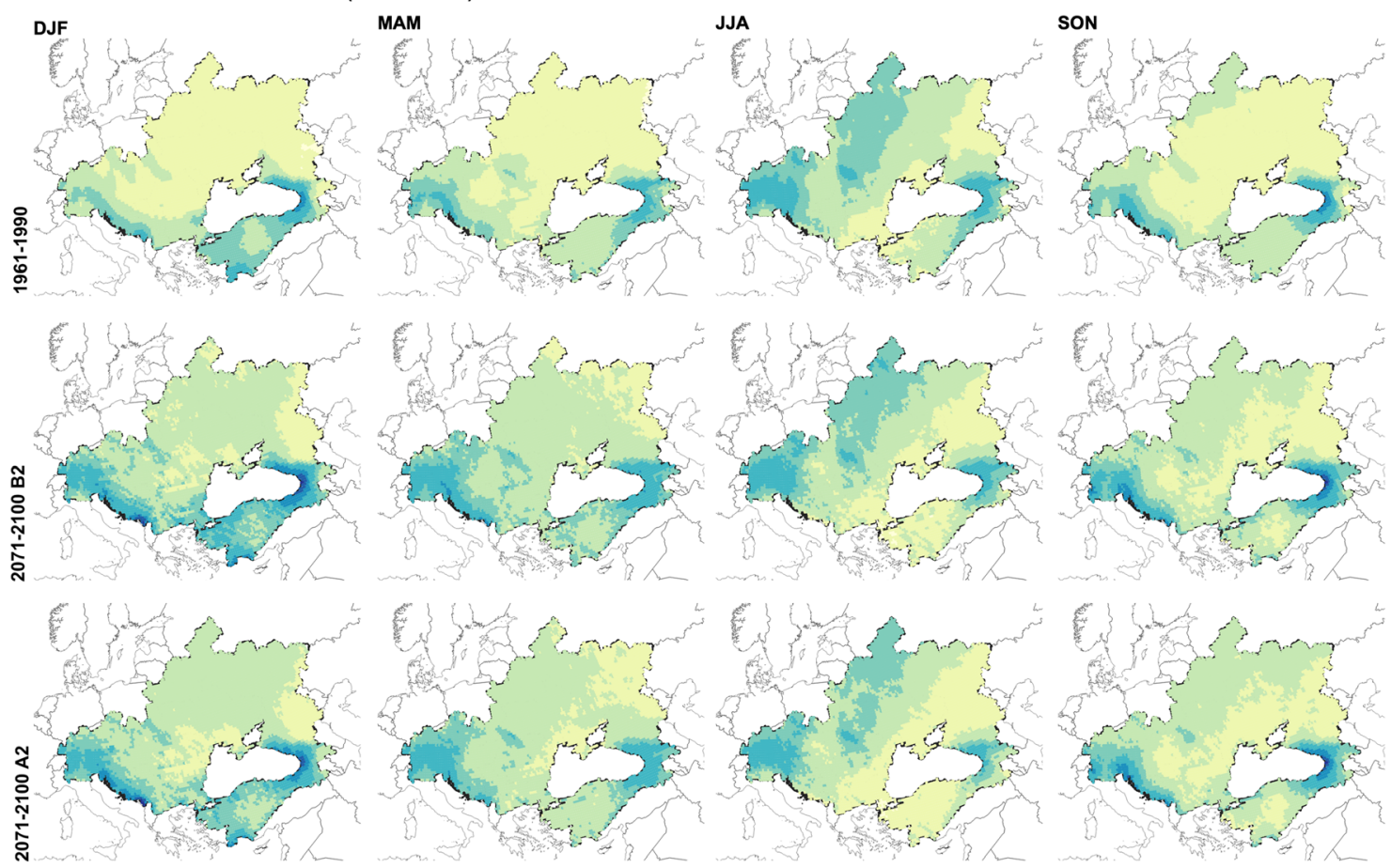

$\mathrm{PCP}$
(mm/month)
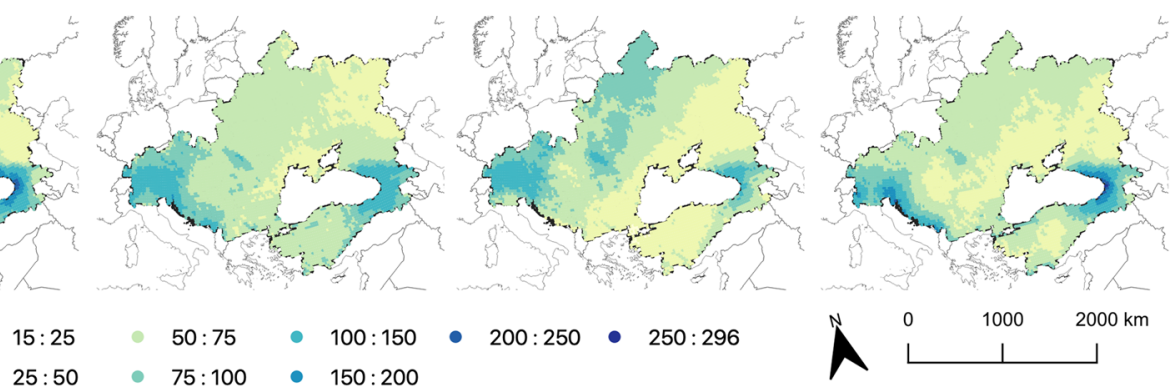

Fig. 17 Seasonal mean cumulative PCP for the historic period (1971-1990) and downscaled scenarios (B2 and A2) for 2071-2100; see Fig. 6 for season symbols
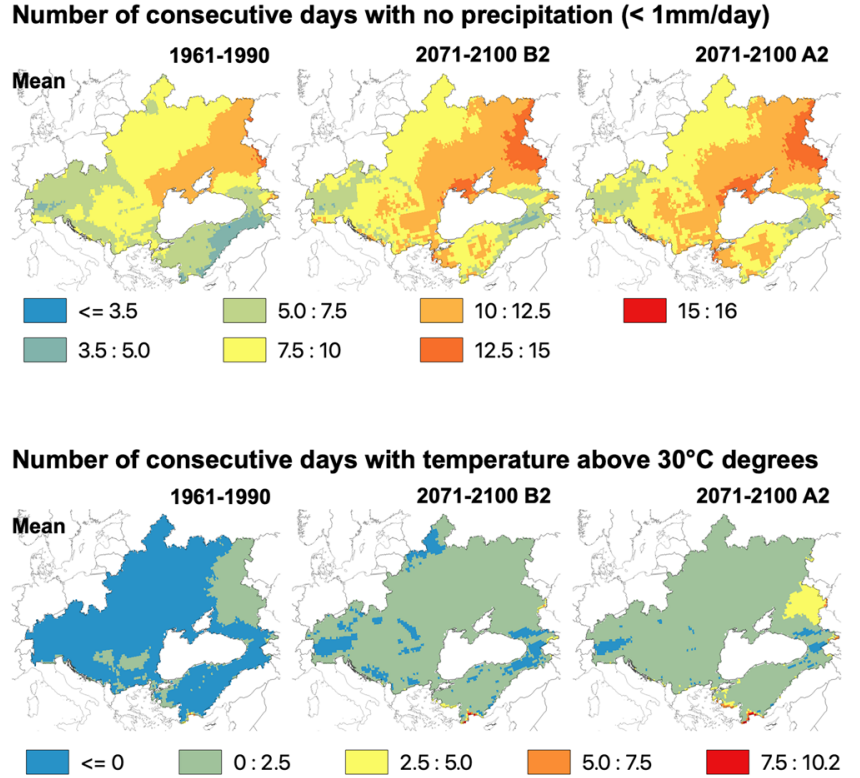

Fig. 19 BSC mean and maximum dry spell duration (top) and heat wave duration (bottom) for the historic period (1971-1990) and both scenarios (B2 and A2) for 2071-2100. The dry spell represents the length of
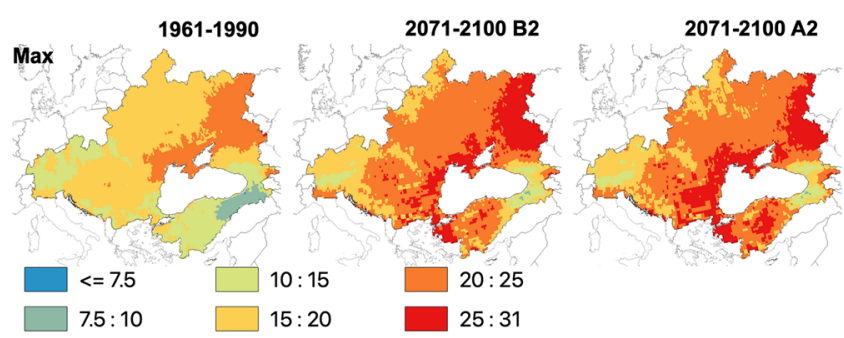

$7.5: 10$

$15: 20$
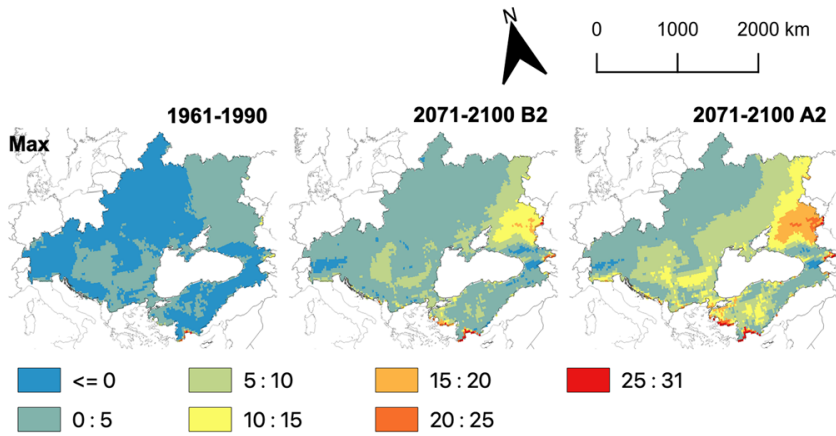

consecutive number of days within 1 month with PCP bellow $1 \mathrm{~mm} /$ day. The heat wave duration represents the number of consecutive days within one month with temperature above $30^{\circ} \mathrm{C}$ 